\title{
Production of paper from mushroom raw materials
}

Kuragina N.S. ${ }^{1}$, Romanovskova A.D. ${ }^{2}$

${ }^{1}$ Volgograd state University, Volgograd, Russia; ${ }^{2}$ Moscow State Pedagogical University, Moscow, Russia

E-mail: kuragina23@mail.ru

Key message. For the first time, ecologically pure $A_{4}$ and $A_{5}$ paper was obtained from aphyllophoroid fungi. Classical methods of mycological research and methods of creating paper web were used.

Keyword. Aphyllophoroid fungi, Volgograd oblast, paper

Today, there are many technologies for making the likeness of the paper materials from wood, fallen leaves, straw, etc. For the first time, we obtained paper from aphyllophoroid basidiomycetes that do not represent nutritional value for the population, but are regularly found on the territory of the Volgograd region on the main forest-forming species of woody plants: Populus nigra L., Quercus Robur L., Ulmus laevis Pall. These are the types of fungi, Cellulariella warnieri (Durieu et Mont.) Zmitr. et Malysheva, Fomes fomentarius (L.) Fr.

The purpose of our research was to develop an ecological and low-cost technology for producing paper from common, but not used by the population of aphyllophoroid fungi. Standard methods of mycological research (collection, light microscopy) and methods of paper production (grinding, bleaching, pressing and drying) were used.

Technology of creation of paper:

1. Samples of dried mushroom were swollen in deionized water, after which they were crushed in a laboratory blender. The grinding time was 15 minutes.

2. Cationic starch was added to the fibrous suspension to increase mechanical strength and thoroughly mixed for 20 minutes.

3. The resulting mass is cooked until a liquid mixture is obtained. At the same time, bleaching agents were introduced into the composition of semi-finished products for discoloration in order to discolor natural coloring substances-lignin.

4. The sheets were formed on 100 wire meshes.

5. The grams were reduced to $160 \mathrm{~g} / \mathrm{m}^{2}$ by diluting the suspension if necessary.

6. The sheets were pressed at a pressure of 4.2 bar for 4 minutes.

7. Dried in a frame at a temperature of $105^{\circ} \mathrm{C}$ for 3 minutes.

8. Testing of sheets: using a micrometer, the grammage, thickness, and specific volume were determined.

In this way, an ecologically pure $\mathrm{A}_{4}$ and $\mathrm{A}_{5}$ paper was obtained. For the production of such paper, you can use the aphyllophoroid fungi Cellulariella warnieri and Fomes fomentarius.

\section{Изготовление бумаги из грибного сырья}

Курагина Н.С. ${ }^{1}$, Романовскова А.Д. ${ }^{2}$

${ }^{1}$ Волгоградский государственный университет, Волгоград, Россия; ${ }^{2}$ Московский педагогический государственный университет, Москва, Россия

Аннотация. Впервые была получена экологически чистая бумага формата $A_{4}$ и $A_{5}$ из афиллофороидных грибов. Применялись классические методы микологических исследований и методы создания бумажного полотна.

Ключевые слова: афиллофороидные грибы, Волгоградская область, бумага

На сегодняшний день существует множество технологий изготовления бумагоподобных материалов из древесины, опавших листьев, соломы и т.п.

Нами была впервые получена бумага из афиллофороидных базидиомицетов, не представляющих пищевой ценности для населения, но регулярно встречающихся на территории Волгоградской области на основных лесообразующих видах древесных растений: Populus nigra L., Quercus robur L., Ulmus laevis Рall. Это такие виды грибов, как Cellulariella warnieri (Durieu et Mont.) Zmitr. et Malysheva, Fomes fomentarius (L.) Fr.

Целью нашего исследования послужила разработка экологичной и дешёвой по себестоимости технологии получения бумаги из часто встречающихся, но не используемых населением афиллофороидных грибов.

В работе применялись стандартные методы микологических исследований (сбор, световое микроскопирование) и методы получения бумаги (измельчение, отбеливание, прессовка и сушка).

Технология создания бумаги:

1. Образцы сухого гриба набухали в деионизированной воде, после чего их измельчали в лабораторном блендере. Время размола составило 15 минут.

2. В волокнистую суспензию добавили катионный крахмал для повышения механической прочности и тщательно перемешивали в течение 20 минут.

3. Полученную массу варили до получения жидкой смеси. Одновременно в состав полуфабрикатов ввели отбеливающие вещества для обесцвечивания природных красящих веществ, лигнина.

4. Листы формовали на проволочной сетке 100.

5. Граммаж доводили до 160 г/м² путём разбавления суспензии при необходимости.

6. Листы подвергали прессованию под давлением 4,2 бар в течение 4 минут.

7. Сушили в раме при температуре $105^{\circ} \mathrm{C}$ в течение 3 минут.

8. Испытание листов: с помощью микрометра определяли граммаж, толщину, удельный объём.

Таким образом, была получена экологически чистая бумага формата $\mathrm{A}_{4}$ и $\mathrm{A}_{5}$. Для производства такой бумаги можно использовать афиллофороидные грибы Cellulariella warnieri и Fomes fomentarius. 